\title{
Time to relax research use of patents
}

\author{
Simon Cohen
}

\begin{abstract}
The conditions under which research is exempt from European patent law are ambiguous, and current judicial interpretation is too restrictive. A more liberal approach would be a welcome boost to small research-based companies.
\end{abstract}

SHOULD scientists be allowed to carry out research using a patented process without either a licence or the permission of the patent-holder? This question is being increasingly raised in both academic and industrial circles, not merely because companies are keen to receive royalties on their technological inventions, but also because the research for which these inventions are used may itself have commercial value. The common interpretation is that research is exempt from patent restrictions; but the reality is more complicated.

One area in which this issue arises is the use of a patented drug in clinical trials designed to test a treatment not covered by the original patent. The borderline between experimental and commercial use of patented subject matter has also come under scrutiny in the dispute between Promega and Hoffmann-La Roche over the use in academic laboratories of the thermostable enzyme Taq polymerase (see Nature 375, 348; 1995).

Another recent case that focused on the so-called 'research exemption' was the unsuccessful bid in the UK High Court by Murex Diagnostics Limited and Organon Teknika Limited to challenge the scope of a patent monopoly awarded to the US biotechnology company Chiron on making and selling test kits for hepatitis- $\mathrm{C}$ virus (see Nature 375, 348; 1995).

Murex had been developing an assay for serotyping the hepatitis- $C$ virus when it was successfully sued by Chiron for patent infringement. Murex wanted to continue research and development on this particular assay, even though its commercial use would infringe Chiron's patent. Ambiguity in the scope of the statutory research exemption meant that, to avoid a further legal challenge, Murex had to reach an agreement with Chiron while awaiting the hearing of its appeal on the first charge.

Under the terms of UK and European patent law, work carried out for 'experimental purposes' on patented subject matter does not constitute an infringement of the patent concerned. But what does experimental purposes mean? It obviously covers fundamental research, including efforts to modify or improve the invention with no commercial goal in mind. But does it include research carried out to demonstrate to a potential customer that a product works, or clinical trials intended to

This is one of an occasional series of articles on intellectual property and the law. demonstrate to regulators that a product is safe and effective?

Such questions are often relevant in patent disputes where both sides have been carrying out research in parallel in the same field. Murex and Organon, if their challenge to Chiron's patent is unsuccessful, will be prevented from continuing to market their own hepatitis-C screening products. But they will also be prevented from developing their product without a licence from Chiron, unless such work is purely experimental.

Despite a prohibition on immediate sales, such companies may wish to continue to develop products - including their use in clinical trials - in order either to be ready to market such products as soon as the relevant patent expires (or is invalidated), or to apply for compulsory licences.

Some of these questions were considered by the UK Court of Appeal in a suit brought by Monsanto Co. against Stauffer Chemical Co. over the herbicide Touchdown. Before a patent challenge from Monsanto, Stauffer had carried out field trials with the herbicide and obtained limited safety clearances. Even though Monsanto's challenge was successful, Stauffer still wanted to carry out more trials to obtain further clearances.

The Court of Appeal ruled that trials carried out either to discover an unknown effect, or to test a hypothesis, can be regarded as experiments. But it added that trials carried out to demonstrate to a third party that a product works, or to collect information to satisfy either a customer or regulatory body, were not acts done for “experimental purposes".

The current law is therefore clear. But one equally clear result is that when a party loses an action for patent infringement, it may have to abandon the research that was the subject of the action, at least until expiry of the patent.

The potential problem for medical research was highlighted in the report Intellectual Property \& the Academic Community, published earlier this year by the National Academies Policy Advisory Group (NAPAG) (see Nature 374, 398; 1995). If a patented substance is being studied for new therapeutic applications, it will at some stage have to be tested on patients - an activity that would constitute patent infringement.

In the United States, the research exemption is restricted to "experimental or other nonprofit purposes'. Although the wording is similar to that of European patent legislation, it has been interpreted by US courts as allowing clinical trials aimed at meeting regulatory requirements for new drugs.

US experience suggests that the scope of what is understood to be 'experimental purposes' in Europe should be widened and clarified. Such a move would have the additional advantage of bringing European and US legislation in line on the issue. This would not need a legal amendment, as the law could be clarified merely by a clear judicial ruling.

Ideally, this clarification would specify that activities such as validation tests should not be considered to infringe a patent. Only real commercial use, involving a financial transaction, should be prohibited. This would enable companies who are successfully sued for infringing a patent or who fail in an attempt to challenge a patent held by another company - to continue to carry out research in an area where they may already be well advanced.

Research of this type could result in a useful modification of the patented invention, which the original patent owner may wish to license or may agree can be produced and sold under licence. Alternatively, the research could lead to a product or process which is sufficiently distinguishable from the original patent that it requires no cooperation from the patent-holder.

Scientists must be given incentives to develop innovative ideas and products, and this means allowing them the monopoly period provided by patents. But at the same time, competitors should be allowed to experiment with such products during the period of the monopoly.

To forbid any unlicensed activity apart from fundamental research during the lifetime of a patent wastes the investment that others have made in the area. Even worse, it risks paralysing associated research. The current interpretation of the research exemption in Europe places a particular burden on research-based companies that may have several promising products in the pipeline but few (if any) generating revenue. A more liberal interpretation would limit the 'winner takes all' effect, and would thus act as a welcome boost to such companies as they strive to get off the ground.

The author is a solicitor at Taylor Joynson Garrett, 50 Victoria Embankment, London EC4Y ODX, UK. 